Authors' version of: Dilkes-Frayne, E. and Fraser, S. and Pienaar, K. and Kokanovic, R. 2017. Iterating 'addiction': Residential relocation and the spatio-temporal production of alcohol and other drug consumption patterns. International Journal of Drug Policy. 44: pp. 164-173. http://doi.org/10.1016/j.drugpo.2017.05.024.

\title{
Iterating 'addiction': Residential relocation and the spatio-temporal production of alcohol and other drug consumption patterns
}

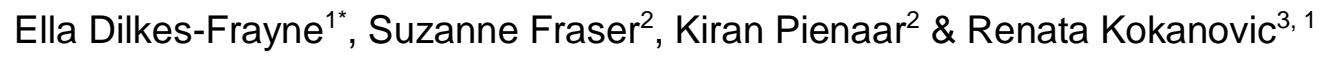

1. Social Studies in Health and Medicine Research Program, School of Sociology, Faculty of Arts, Monash University, Melbourne

2. Social Studies of Addiction Concepts, National Drug Research Institute, Faculty of Health Sciences, Curtin University, Melbourne

3. Centre for Applied Social Research, RMIT University, Melbourne

\section{Acknowledgements}

The authors extend sincere thanks to the interview participants for generously sharing their stories. The research reported in this paper was conducted by researchers from Curtin University's National Drug Research Institute (NDRI), in collaboration with Healthtalk Australia, Monash University and the University of New South Wales' Centre for Social Research in Health (CSRH), and funded by an Australian Research Council Discovery Project DP140100996. Suzanne Fraser is funded by an Australian Research Council Future Fellowship (FT120100215). NDRI is supported by funding from the Australian Government under the Substance Misuse Prevention and Service Improvement Grants Fund. CSRH is supported by a grant from the Australian Department of Health. Interviews were conducted by Kiran Pienaar, Ella Dilkes-Frayne, Jeanne Ellard and Jamee Newland. 


\title{
Iterating 'addiction': Residential relocation and the spatio-temporal production of alcohol and other drug consumption patterns
}

\begin{abstract}
Addiction is generally understood to be characterised by a persistent pattern of regular, heavy alcohol and other drug consumption. Current models of addiction tend to locate the causes of these patterns within the body or brain of the individual, sidelining relational and contextual factors. Where space and place are acknowledged as key factors contributing to consumption, they tend to be conceived of as static or fixed, which limits their ability to account for the fluid production and modulation of consumption patterns over time. In this article we query individualised and decontextualised understandings of the causes of consumption patterns through an analysis of accounts of residential relocation from interviews undertaken for a large research project on experiences of addiction in Australia. In conducting our analysis we conceptualise alcohol and other drug consumption patterns using Karen Barad's notions of intra-action and spatio-temporality, which allow for greater attention to be paid to the spatial and temporal dimensions of the material and social processes involved in generating consumption patterns. Drawing on 60 in-depth interviews conducted with people who self-identified as experiencing an alcohol and other drug addiction, dependence or habit, our analysis focuses on the ways in which participant accounts of moving enacted space and time as significant factors in how patterns of consumption were generated, disrupted and maintained. Our analysis explores how consumption patterns arose within highly localised relations, demonstrating the need for understandings of consumption patterns that acknowledge the indivisibility of space and time in their production. In concluding, we argue for a move away from static conceptions of place towards a more dynamic conception of spatio-temporality, and suggest the need to consider avenues for more effectively integrating place and time into strategies for generating preferred consumption patterns and initiating and sustaining change where desired.
\end{abstract}

\section{Key words}

Addiction; Karen Barad; patterns of alcohol and other drug use; place; time; relocation 


\section{Introduction}

Medical and neuroscientific approaches to addiction tend to locate its causes within the body or brain of the individual, and to portray addiction as a disordered or diseased personal state (Keane, 2002). Such accounts, however, obscure the importance of social contexts to addiction issues and how consumption patterns change over time, with the effect of constructing addiction as an immutable flaw located within the individual experiencing it (Fraser, Moore \& Keane, 2014). In response, place-based and geographical accounts of alcohol and other drug consumption and addiction have grown in prominence within the social sciences aiming to explain how consumption and addiction are shaped by social and spatial contexts (Jayne, Valentine \& Holloway, 2016). While these provide less individualising understandings of addiction, they also have limitations in that they tend to treat space and place as stable and unchanging, limiting their ability to account for the temporal development of patterns and change. Taking inspiration from recent moves towards more processual and relational accounts of consumption and addiction, this article aims to complicate common static and decontextualised understandings of addiction by exploring how alcohol and other drug consumption patterns are generated, disrupted and maintained in highly localised, yet constantly shifting, sets of relations.

The relational ontology of Karen Barad's work, in particular her conception of the collective spatio-temporal generation of agency and action, is well suited to this task. We draw on her notion of intra-action to treat consumption not as emerging solely within the individual. Here, agency is not taken to be a personal attribute of the sovereign subject. Instead it emerges in the complex relations of many phenomena, such as drugs, bodies and places. The spatio-temporal aspect of Barad's work is crucial to our task of accounting for how patterns emerge over time, and how spaces have dynamic effects on consumption.

In order to explore the spatio-temporal generation of consumption we analyse accounts of consumption patterns in personal stories of residential relocation. These accounts are drawn from interviews conducted in Australia with 60 people who selfidentified as experiencing an alcohol or other drug addiction, dependence or habit. In reading these accounts of relocation through Barad's concepts of intra-action and spatio-temporality, our analysis explores how patterns of consumption emerge, and are disrupted or maintained through changes in the spaces and routines of participants' lives. Our analysis suggests that accounts of the role of space in 
consumption must incorporate a temporal dimension to account for the development of patterns as well as the dynamism and change that spaces themselves undergo. In doing so, we reinterpret consumption patterns, the changes they undergo and apparent reversions to old patterns (or 'relapse' in common parlance), as iteratively constituted in the spacetimes of daily life.

We begin by exploring how current conceptions of addiction deal with patterns of consumption, and reviewing the social science literature on place and relocation in alcohol and other drug use. We then outline our theoretical approach and methods. We go on to analyse accounts of relocation, noting the limitations of conventional place based accounts and finding that Barad's notions of spatio-temporality and intra-action offer richer understandings as well as room to escape the essentialising implications of models that present space as stable and apparent returns to old patterns of drug use as the effect of internal individual dynamics. The paper concludes by calling for accounts of consumption patterns, place and relocation that attend as much to time as to space, such that less individualising and less stigmatising approaches to addiction may be produced.

\section{Background: Conceptualising addiction}

Addiction is variously defined as a brain disease, a medical condition, the result of a weak will, or a moral failing. In each case, the deficit or pathology is located within the body or brain of the individual, and patterns of consumption are treated as an effect or symptom of an underlying internal disorder (Keane, 2002). The Diagnostic and Statistical Manual of Mental Disorders, $5^{\text {th }}$ edition (DSM-5) defines substance use disorders with reference to 'persistent', 'recurrent' or 'continued' alcohol and other drug use, but also requires the presence of other indicators, such as tolerance, withdrawal, compulsion, or effects on responsibilities and relationships (American Psychiatric Association, 2013). The International Classification of Diseases (ICD-10) takes a similar approach, focusing on compulsion, loss of control, withdrawal, tolerance, neglect of alternative interests and harms to health, such that someone can be currently abstinent and still receive a diagnosis of 'dependence syndrome' (World Health Organization, 1992). In a similar way, neuroscientific accounts attend to neurological markers of brain disease rather than patterns of consumption per se (Keane, 2002). In all these cases, heavy regular consumption emerges as a symptom of an underlying cause, or a trigger of a disease or disorder that produces continued consumption. In short, patterns of consumption are primarily of interest where they produce other physiological or social effects deemed harmful. 
Perhaps because these key diagnostic models emphasise symptoms and effects beyond patterns of drug use, they tend to portray addiction as a static 'disordered' or 'diseased' state. Approaching addiction in this way has been criticised as unable to attend to, or even as actively obscuring, the fluidity and dynamism of patterns of consumption (Keane, 2002; Moore, 1992). Dependence or addiction may arise at a particular time and then lapse or disappear, as noted in research addressing alcohol and other drug careers, pathways, journeys and transitions, as well as in life course approaches to addiction (Hser, Longshore \& Anglin, 2007; Mayock, 2002; Williams, 2012). In this sense, addiction is not easily classifiable as an inherent or static characteristic of a person, body or brain (Fraser, Moore \& Keane, 2014). When looked at over time, changes in consumption become more evident and causal factors beyond individual flaws or problems are necessarily implicated (Duff, 2014; Fraser, Moore \& Keane, 2014). Investigations into the temporal processes by which patterns of consumption emerge, continue and change are necessary in order to account for the dynamism in consumption patterns over time and to provide analyses that exceed addiction ontologies based on individual pathology.

\section{Literature review: Drugs, place and relocation}

While researchers have long acknowledged the importance of environment for shaping alcohol and other drug use (Alexander, Hadaway \& Coambs, 1980; Zinberg, 1986), the salience of environmental factors and social context still tends to be neglected in favour of pharmacological and biological understandings of drug effects (DeGrandpre, 2006). In recent years, however, place-based understandings of consumption have been growing in prominence (Cooper \& Tempalski, 2014; Jayne, Valentine \& Holloway, 2016; Wilton \& Moreno, 2012). Analyses based on the 'risk environment' approach have also gained attention for examining how risks usually ascribed directly to drug use are actually contingent upon specific local environments (Duff, 2011; Moore \& Dietze, 2005; Rhodes, 2002). Ethnographic and other qualitative research has likewise proven crucial for presenting highly detailed, situational accounts of places and times of consumption (e.g. Bourgois \& Schonberg, 2009; Duff, 2014; Malins, Fitzgerald, \& Threadgold, 2006; Moore, 2004; Parkin, 2013).

While these literatures contribute to understandings of the relationship between individual experiences of drug use and the contexts in which it occurs, they often 
remain limited by a tendency to treat space and place as atemporal or fixed, having stable characteristics and effects over time. Static conceptions of place overlook how the character and dynamics of space change as people and other phenomena move through it, and underplay the importance of these changes for health effects (Cummins, Curtis, Diez-Roux \& Macintyre, 2007; Morris, Manley \& Sabel, 2016; Rainham, McDowell, Krewski \& Sawada, 2010). Treating place as static entails certain assumptions about the causes of change in consumption patterns. In particular, it becomes difficult to account for change without referring back to personal characteristics, essentialised as intrinsic to the individual.

Some research has explored space and time specifically with regard to narratives of self and community in the drug trade. In her ethnography of communities living with drug trade violence in Medellin, Colombia, Riaño-Alcalá (2010) explores how narratives played a role in imbuing the city with sense and meaning, linking people to past events and providing a sense of continuity. Other narrative research has focused on how particular kinds of narratives - such as the linear addiction stories of 12-step models that centre on ruin (in addiction) and redemption (in recovery) construct a temporality of addiction to tell a story about the addicted self, and enable a new subjectivity to emerge through owning this narrative (Summerson Carr, 2011). In this way, addiction narratives tend to foreground the flawed self, neglecting accounts of the material relations of alcohol and other drug use, and the spatiotemporal constitution of both consumption and subjectivity. Similarly, narratives that focus on place or place-making tend to privilege the meanings of particular places rather than focus on the ways in which places help to materialise particular consumption practices.

Despite increasing interest in mobilities across the social sciences and within alcohol and other drug research (Adey, et al., 2014; Duff \& Moore, 2014; Jayne, et al., 2012; Martinez, Lovrick \& Kral, 2014), one aspect of the dynamic relationship between alcohol and other drug consumption and place that has received little attention is residential relocation. Several studies conducted in the United States focus directly on relocation and associated changes in alcohol and other drug use, but this work is narrow in focus, only attending to disadvantaged populations or neighbourhoods (Cooper, et al., 2013; Genberg, et al., 2011; Linton, et al., 2016). Some research has explored how child and adolescent residential mobility affects later alcohol and other drug consumption, suggesting that high residential mobility during childhood is a risk to later health and well-being (DeWit, 1998; Stabler, Gurka \& Lander, 2015). Limited 
research indirectly demonstrates the difference relocation can make to consumption patterns while focusing on other issues (Green \& Pope, 2008; Moore, 1992; Waldorf, Reinarman \& Murphy, 1992). However, critical qualitative and geographic research remains to be undertaken on the role of residential relocation in the development of consumption patterns.

This lack of explicit attention is surprising given that relocation is a key principle of residential treatment modalities, which are based upon the assumption that moving someone out of their everyday environment into a 'therapeutic' milieu or landscape facilitates change (Love, Wilton \& DeVerteuil, 2012). Relocation also features in accounts of so-called 'natural' or 'spontaneous recovery', that is, reduction or cessation of consumption without formal treatment or participation in self-help programs (Granfield \& Cloud, 1999; Maddux \& Desmond, 1982; Waldorf, Reinarman $\&$ Murphy, 1992). Relocation for the purpose of ceasing consumption is often informally referred to as a 'geographic cure' or 'doing a geographical'. While the studies cited above are now some decades old, the geographic cure still receives attention in Alcoholics and Narcotics Anonymous resources and self-help programs (Alcoholics Anonymous Australia, 2016). In these contexts 'doing a geographical' is often presented as a fallacy - "part of the addict's denial system" and "avoidance" strategy (Granfield \& Cloud, 1999: 92), or akin to "changing deckchairs on the Titanic" (Alcoholics Anonymous Australia, 2016). Relocation appears destined to fail in that 'addicts' can never escape themselves and their problems even where they have changed their circumstances, routines and social networks. In these cases changes to patterns of lighter consumption are considered temporary, and subsequent changes to heavier patterns are seen as a return to the dysfunctional that must inevitably accompany the damaged or diseased self. The apparent conflict here between the rather negatively inflected notion of 'doing a geographical' and the positively inflected notion of committing to a residential treatment program highlights the lack of clarity around the effects of place and movement on consumption patterns, and the role of relocation in bringing about change.

While understandings of consumption that take place and context into account have proliferated in response to individualising and pathologising accounts of addiction, temporality remains underutilised. Thinking space and time together is crucial for understanding how places contribute to dynamic consumption patterns. Here we take up Karen Barad's theorisation of spatio-temporal emergence as a means of doing just this. 


\section{Approach}

In this article we propose a reframing of place to address its indivisible temporal dimensions in order to elucidate the spatio-temporal emergence of consumption patterns. Emergent approaches move away from a focus on the characteristics of places towards a focus on processes and relations, emphasising the continual contestation and negotiation involved in making and remaking places and their effects (Massey, 2005; Murdoch, 2006). Processual approaches offer tools for studying the ways in which places give rise, within and across time, to particular practices, agencies, repetitions and disruptions (Dilkes-Frayne, 2014; Fraser, 2006). Relational ontologies also provide a way to challenge the ethics and politics of concepts (such as 'addiction') that rely upon essentialising discourses of individual pathology, disease or deviance (Fraser, Moore \& Keane, 2014; Fraser \& valentine, 2008; Keane, 2002).

To conduct our analysis we draw on Karen Barad's feminist science studies theorisation of two key concepts, intra-action and spatio-temporality, taking up the approach this article's second author first took in an earlier article on space-time in drug use (Omitted, 2006). Since that piece was published Barad's work has figured in a small body of social scientific research on drug use (Pienaar, et al., 2016; Poulsen, 2015; Seear, 2013), but remains to be exploited to its full potential, particularly her theorisation of spatio-temporality.

In her paper 'Posthumanist Performativity' (2003), Barad combines concepts of space-time with philosopher Judith Butler's notion of performativity to generate new politically savvy perspectives on the agency of objects, the nature of matter, and causality. This approach, which had figured in Barad's work for some years, is termed 'agential realism'. In 1998 she used the work of physicist Niels Bohr (in particular his work on the role of scientific research in constituting material realities) alongside Butler's to elaborate the concept, arguing that contrary to received wisdom, "Subjects" and "objects" do not preexist as such, but are constituted through and within particular practices' (1998: 106). More specifically, she argues against the existence of 'relata' (pre-existing components of objects in relations). Following Bohr, she counters the notion of relata by positing the 'phenomenon', which she defines as comprising 'ontologically primitive relations - relations without pre-existing relata'. The phenomenon replaces the notion of the independent object that possesses inherent properties (2003: 815). It also problematises the 
conventional formulation of causality, substituting it with 'intra-action', defined as distinct from 'interaction', which 'presumes the prior existence of independent entities/relata' (2003: 815). Agency is seen here not as 'an attribute' of any single pre-existing entity but as emerging from the intra-action of phenomena, a product of 'the ongoing reconfigurings of the world' (2003: 818). This rethinking of agency and ontology opens up ways of understanding the co-construction - the fluid intra-action - of all kinds of phenomena, such as drugs, places and temporalities, and of course addiction.

Of explicit relevance to the issue under consideration here is what Barad calls, after post-Newtonian physics, the 'space-time manifold' (2001: 93). In keeping with her formulation of the phenomenon and intra-action, Barad conceptualises space and time as mutually constitutive, and as productive of material realities:

[The dynamics of intra-activity] is not marked by an exterior parameter called time, nor does it take place in a container called space, but rather iterative intra-actions are the dynamics through which temporality and spatiality are produced and reconfigured (2001: 90).

Here, Barad recognises that time and space are more than pre-existing agencies that act on pre-existing subjects and objects to produce stable outcomes. Rather, they are always already the product of each other and of specific intra-actions with other intra-actively produced phenomena. Intra-actions between a vast array of phenomena are thus involved in the iterative materialisation of bodies, agencies and action. In the process of this iteration material forms and agencies shift, producing a temporality through which spaces, bodies and their effects on each other are recreated or changed.

Adopting this notion of iterative intra-activity for our analysis means space and place, heretofore theorised in isolation from time, must now be understood as always already temporal and processual. Following this line of thought, drug consumption patterns become the effect of specific iteratively intra-active spatio-temporalities, materialised in particular ways through the intra-actions of phenomena in particular 'spacetimes', to use Barad's (2003) neologism. Where no singular or internal cause can be attributed to the generation of a body's agency, and where each action requires collective intra-action in order to be performed, the repetition of consumption practices cannot be assumed to be caused by a single factor within an individual body, but must be continually produced through a range of spatio-temporal relations and phenomena. Places, in this way of thinking, are collections of emergent effects, 
unstable, forever changing over time and in relation to other phenomena. Alcohol and other drug consumption, too, emerges through these intra-actions and then feeds back into the materialisation of particular spaces in an ongoing, iterative process. As we will see, taking this approach allows us to better understand the coconstitutive relationship between drug use patterns and place.

\section{Method}

The qualitative research project on which this article is based was designed to elicit personal accounts of alcohol and other drug addiction, dependence or habit to create an innovative web-based resource (Omitted). The project is a collaboration with Healthtalk Australia (http://healthtalkaustralia.org), an Australian research consortium that conducts qualitative research into personal experiences of health and illness. Healthtalk Australia collaborative projects use a research methodology developed by Oxford University's Health Experiences Research Group (HERG, 2010), which involves collecting and analysing health experiences and presenting these on a carefully curated online resource.

In-depth qualitative interviewing was used to generate accounts of alcohol and other drug consumption from a diverse range of people $(\mathrm{N}=60)$ who responded to a recruitment flyer that opened with the question: 'Do you consider yourself to have a drug habit, dependence or addiction?' The flyer was circulated through alcohol and other drug sector newsletters, treatment services, drug user organisations, community noticeboards and social media. All participants described ongoing $(n=47)$ or past regular use $(n=13)$ of a range of licit and illicit drugs including alcohol, cannabis, crystal methamphetamine, heroin, prescription and over-the-counter drugs (e.g. benzodiazepines, codeine) and various 'party drugs' (e.g. MDMA, GHB, ketamine). 'While many of those interviewed had experience of alcohol and other drug treatment programs, we also interviewed several people who had neither participated in such programs nor accessed any treatment services. Detailed information about the people interviewed is presented in Appendix 1. All participants provided informed written consent. Each participant was given a pseudonym and all identifying details were removed from the transcripts to protect the participants' identities. The study was approved by [University name] Human Research Ethics Committee (HR 55/2014). Interviews took place in urban and regional Victoria and New South Wales, Australia. Consistent with common research practice in the Australian alcohol and other drug context, participants were reimbursed $\$ 50$ for their 
time (Fry \& Dwyer, 2001). All interviews were conducted in person and were audiorecorded and transcribed verbatim.

The interviews began with an open-ended invitation to participants to 'tell us their story'. Participants were asked about their experiences of living with an alcohol and other drug addiction, dependence or habit, including how consumption fits into daily life, experiences of treatment, and future plans. The remainder of the interview drew on a list of key questions, including questions about treatment, health and well-being and stigma and discrimination. In-depth interview methods tend to produce narratives that posit the agency of the human subject telling the story, and organise events around the subject's 'own' experience. In these ways such methods do not always mesh well with theoretical approaches such as that of Barad. However, following Jackson and Mazzei (2011), it is possible to instead treat the stories told in the interviews as partial, not as unproblematic representations of the truth of experience but as performative enactments of particular consumption narratives. Here, particular enactments of spatio-temporality are enabled and constrained by the interview method and the context of the telling of these narratives. Working with these accounts, then, involved a two-step process. First, the interviews were analysed using an iterative inductive approach in which a preliminary list of codes was drawn up based on emerging themes, and the data were coded with the aid of the NVivo qualitative data management software. Second, we drew on the thematic code relating to residential relocation to read and 'think' the data through Barad's concepts of intra-action and spatio-temporality and the methods outlined by Jackson and Mazzei (2011). This allowed us to understand participant agencies and consumption patterns as partially co-produced in the interview process in concert with the spatiotemporal phenomena under discussion.

\section{Analysis}

Residential relocation was common among our participants, and many discussed its impact on their consumption. Relocation included moving to: a new house or living arrangement; a new suburb, city, town, state or country; into or out of residential treatment (such as rehabilitation or detox programs); and in some cases, custody or homelessness. Reasons for moving included work or study, family, a change in lifestyle, to access treatment, or specifically to change alcohol and other drug consumption. Their stories articulate a diversity of experiences, but also a common thread: the relationship between moving and patterns of consumption. Below we discuss the ways these accounts of relocation enact the generation, disruption or 
maintenance of consumption patterns. In our analysis we aim to highlight the highly spatio-temporally specific ways in which patterns of consumption arise and subside.

\section{Generating new consumption patterns}

Many who spoke about relocation noted that being engaged in new spaces, rhythms and routines generated novel access to and patterns of consumption. Josie (38 years old) recalled being removed from her childhood home in her early teens by child protection services after experiencing family violence. Placed in a group home for girls, Josie said she was unhappy and as a result she left. Not knowing where else to go, she began living on the streets. She recounted spending her days and nights with a group of young people with whom she began taking speed each day as a way, she said, to feel better and 'block' her past experiences:

You'd wake up and straight away you thought of alcohol or drugs and, you know, you wanted something [...] Our life back then was just driven to make us feel better [...] that was our train of thought really for the day.

Here Josie describes how poor sleeping conditions and the need to be 'on alert' initially encouraged her to consume amphetamines (or 'speed'), but she eventually found this took a toll on her body and mind, and she began taking heroin to help her sleep:

We usually crashed in a park under some big trees or under a bridge. Yeah, we'd stay there, and it was hard because it was cold and horrible weather. So we did the best we could getting blankets and stuff, sleeping bags, but [...] you're lying on the street and you are listening to the cars and the trains and you just want to close your eyes, but every time you close your eyes you get a big beep of horns or, you know, some distraction. We used to go to sleep eventually, but it wasn't easy [...] that's when I started to get into the heroin, to come down and actually sleep.

In Josie's account, moving onto the street brought her into contact with a new set of relations that facilitated her consumption. Her experience of family violence and homelessness intra-acted with the material and social conditions of living on the street to generate a practice of sourcing speed and, over time, heroin each day. A new pattern of heroin consumption materialised, which she says continued on and off into her adulthood.

Artemis (28) also linked place with his consumption patterns. Born overseas, he moved to a large Australian city in his teens. Describing his teenage self as 'very anti-drugs', he said that prior to moving his drug consumption was limited to drinking 
alcohol and occasionally smoking cannabis. When he moved to Australia, however, he recalls his interests and practices changing:

Just from that point on I became interested in trying different things [...] I came here when I was in my early twenties and it was all very new to me and I had a new sense of independence, and I was meeting a lot of different types of people and really starting to experience - although l'd gone out to bars and clubs before that, now I truly understood what it meant to be a gay man and to party, which is you know, some of the [...] best times l've ever had in my life. So, I tend to think very fondly of drugs, because they are wrapped up in that whole, you know, coming-of-age adventure here in [this] beautiful [city]. Reflecting on the few years since moving to Australia, Artemis said his sense of life in the city was generated in part through the temporalities of socialising and partying as part of the city's vibrant gay nightlife scene. Through these connections a pattern developed of smoking cannabis most evenings and taking MDMA, GHB, cocaine, crystal methamphetamine, ketamine and poppers on nights out every week or two.

These two accounts begin to articulate some of the ways in which moving can generate new relations through which particular patterns of consumption intraactively emerge. The new engagements of life on the street (in Josie's case), and of partying and work (in Artemis's), posed different opportunities for, and expectations of, consumption. At times the very desirability of consumption arose specifically from the break relocation created from past spatio-temporalities and the experiences and events they had materialised - difficult experiences at home for Josie, and an 'antidrugs' past for Artemis. In each of their accounts, moving acted as a catalyst for the emergence of new patterns of consumption through the intra-actions of the spaces and relations in which they became engaged. Once set in motion, these patterns could be maintained (re-iterated) or disrupted, processes to which we now turn.

\section{Disrupting existing consumption patterns}

Disruption of existing consumption patterns around the time of relocation arose in the stories of numerous participants. Ethan (39) gave an account of taking speed and methamphetamine on and off since his early twenties, sometimes heavily. In his early thirties, after stopping and resuming consumption several times, he recalls deciding to move interstate to help him stop again:

I moved interstate and that was good for a while. I remember three months of being really excited. It was a new city; I wasn't using drugs because I didn't have drug contacts there. 
According to Ethan, the move to a new city disrupted his access to drugs as his social networks changed, facilitating a break from his previous pattern of daily use. However, over time, with a new job, social group and opportunities for partying, the intra-activity of the city shifted.

At some point, I started going out to clubs, maybe having some Es [ecstasy], some pills and then I [...] found a contact or someone who could get speed and then, once I managed to find that, I just wanted to get it all the time [...] and eventually [...] my addiction just started again.

While relocation initially disrupted his relations with stimulants, the move and the spatio-temporal dynamics of the new city appeared to have an unstable effect: these phenomena produced a break in his consumption, but as Ethan became more involved with work and partying, his access to and desire for stimulants changed, rematerialising his consumption of speed and later methamphetamine, and recreating patterns he recognised as his 'addiction'. Later moving out of the city to attend residential treatment in a regional area, he sought to mobilise a new spatiotemporality to further disrupt his consumption, a change he felt unable to achieve in the city.

Like Ethan, Nick (50) spoke of moving with the intention of changing his pattern of heroin use. Thinking back to his late twenties he recalled taking heroin regularly for several years in Australia before deciding to move back to Greece, where he had been born. He says of the time:

1986 was the worst year of my life, as far as heroin goes. I was doing a lot of it and wasting a lot of money. I was nearly [overdosed] a couple of times back then, and I went to Greece to clean up. And, yes, stayed 10 years, did the army, got married, had our first child over there.

[...] Whilst I was in Greece, the lifestyle suited me. I was the breadwinner. I was doing a very heavy job and I enjoyed it. I was being talked about in the village good, you know, like I was being praised [...] and I was proud [...] I was also managing the village soccer team, and I was always on the go [...] working, looking after the oval on my own time, cutting the grass and doing the lines and everything [...] really getting involved. And I thought, it can't get any better, you know. In Greece, you know, the lifestyle it just suited me. But when we ran out of places to live [...we were] not forced to come back but it seemed a better option. Deep down I knew, deep down I thought, 'I shouldn't really go back to Australia,' because of the fear of using again. 
In Nick's account, the move back to Greece facilitated a change that had felt impossible to him in Australia. Moving, he says, enabled him to live without heroin for ten years, a substantial disruption from his previous pattern of consumption. Because of the intra-actions of his Australian life that had held his heroin consumption in place prior to moving away, he was concerned about the effect returning might have on him, not wanting to resume heroin use at that time. Indeed, some time after returning to Australia, Nick says, he began experiencing difficulties finding work and supporting his family, and resumed taking heroin.

While Nick and Ethan's stories could both be read as efforts at a 'geographic cure' that ultimately failed, or as attempts at recovery that ended in relapse as a result of ongoing personal pathologies, we suggest that such readings would neglect the effect of place and discount the significance of those times during which consumption did not occur. Nick says moving to Greece enabled him to shed his desire for heroin. His return to Australia brought with it new challenges and a strong sense of loss. This was not simply a return to the same place, but the generation of a new spatiotemporality in which heroin again became a way of coping with his (new) situation. For Ethan, on the other hand, consumption re-emerged not because he moved back to where he had lived previously, but because the place he was living in changed over time, intra-actively reproducing his desire for and pattern of regular consumption. To treat these new consumption patterns as relapses, or consider them as the inevitable effects of addiction would be simplistic. Instead, consumption patterns were disrupted or terminated, and produced anew with each move.

Ethan and Nick both present their decisions to move as voluntary efforts to change their use. The next two cases portray rather different circumstances in which relocation was not always voluntary, including in times of incarceration and residential treatment. Tiffany (33) recalled starting to take methamphetamine in her early twenties. After experiencing domestic violence, leaving her partner and resigning from her job, she says her consumption increased and she began taking it every day and supplying it to friends to financially support her own consumption. Soon after, she was arrested and given a two-year custodial sentence and her children went to live with her parents. When she was taken into custody, she says, her desire to take methamphetamine disappeared:

I just couldn't risk it [taking methamphetamine] in jail, like [...] I never craved it. I never thought about it. I'm just in this space where [...] if I don't hang 
around the people that I do, not the area, if I change [that], I really don't have

a problem. Like, I find that I can manage [without methamphetamine].

According to Tiffany, being in the restrictive prison space and ceasing to be around the people and places linked to her consumption, she no longer 'craved' methamphetamine, and her 'problem' disappeared. After a year in prison without methamphetamine, Tiffany was determined to avoid it when she was released on parole. Abstinence from methamphetamine was a condition of her parole and she was subjected to regular urine tests. She spoke of how living with her parents facilitated her abstinence:

I said to my dad, 'Look, I'm here now, I need to do my responsibilities'. [Living here and caring for my children] keeps me clean too, it keeps me away from people [I used to take methamphetamine with...] it was like a totally changed thing.

While Tiffany recalls feeling like she had 'totally changed' in the absence of methamphetamine, she also said that around six months later her relations with her family became strained, and her desire to consume returned:

Me and my mum have this really, like, mother-daughter relationship, rocky [...] Whenever she's angry, she goes, 'You went to jail, you're an embarrassment to our family; you and your brother are just addicts' [...] She's like my trigger. So me and her had an argument [...] and I said ' $F$ this, I'm going to go and pick up and use,' so I rang up [someone who sold me methamphetamine] and relapsed.

In this account Tiffany presents her attempts to create a new spatio-temporality without methamphetamineas compromised by her mother's recriminations. Here, Tiffany's consumption patterns can be read as re-emerging in the antagonistic spatio-temporality of the family home. Later, having tested positive in a urine drug test, was returned to custody. Eventually released on parole to a therapeutic community, her consumption patterns were again disrupted by the relocation. While Tiffany frames her return to consumption as 'relapse', this framing obscures the fluidity of her consumption patterns over time and in relation to the various places where she resided. In this way, her story performs an alternative account of consumption, emphasising spatio-temporal dynamics rather than the internal pathology commonly implied by notions of relapse.

For other participants, the disruption accompanying relocation was presented as very short lived, uniquely entangled with particular treatment spatio-temporalities. For example, after developing a daily pattern of alcohol and benzodiazepine 
consumption, Emma (42) said, she reluctantly went to a seven-day residential detoxification unit (detox) at the request of her husband and mother. She describes how the caring and supportive environment gave her time and space to reflect on the difficulties of her home life:

It was the best thing that ever happened. The people at [the service] were just incredible. Like I just never knew that there was such caring people out there [...] And I think, looking back on it, I enjoyed it too much. It was a way for me to escape the anxiety I had at home of being a mum — which I wasn't coping with at all-being a wife and earning money [...] So being away from all of that and being, having my own room and having meals and having friends around [...] people to talk to, I didn't care about drinking. I didn't crave it once. So that was when I went, 'Ah, I think I know what I'm running away from.' While in the detox unit, Emma said she no longer felt a 'craving' to drink, and the absence of this desire allowed her to reflect on the relationship between her drinking at home and the anxiety she felt about her family responsibilities and working life. Upon reflection, her previous drinking patterns, and what she describes as a 'craving' alcohol, now appeared to be related to her desire to 'escape' the routines that had developed in the spatio-temporalities of her home life. Moving into the detox disrupted these routines, however, this relocation could only be temporary, and she soon had to return home:

We were all of us crying and hugging because we thought finally-you know, after seven days [laughs]—finally, you know, I was cured. But then I remember sitting outside [my house] and just going, 'Oh my God, it didn't work.' [...] l'd realised straight away that, no, I want to drink now.

Emma recalls her family thinking her time in detox had 'cured' her, and that she would be able to remain abstinent upon returning home. However, as she explains, her home situation had remained largely unchanged, and once home she found a desire to drink emerged again. Again, here we can say that the pattern of daily drinking, which was intra-actively produced through her daily routines, gradually rematerialised.

Across the stories of disruption presented here we find the desire, need or compulsion usually ascribed to the individual in common in accounts of addiction appears to be generated and disrupted through highly localised sets of relations or circumstances. The desire to consume could vanish quickly under new spatiotemporal conditions. While each participant eventually took up consumption again, reading these accounts as inevitable 'relapses' neglects the role of situation in this 
process - that is, these were not necessarily a return to old patterns, but new articulations of consumption that emerged through highly situated spatialtemporalities. As such, the recurrence of consumption cannot be taken simply as repetition, the predictable result of a stable pathology inhering in the individual, as is commonly assumed in notions of relapse. Instead they can be seen as new iterations in the new space-times of daily life. Indeed, as we elaborate in the following section, the maintenance or continuity of a particular pattern of consumption or nonconsumption could not be assumed, as it had to be iteratively created not just through individual acts of will, but through the intra-activity of an array of spatiotemporal practices and phenomena, themselves iteratively created.

\section{Maintaining patterns of consumption and abstinence}

The stories presented so far have mapped some of the ways spatio-temporal dynamics featured in participant accounts of changes in their consumption patterns. We now explore patterns of both consumption and abstinence that go unchanged through relocation, and the collective efforts required to maintain this constancy. According to some participants, relocating initially disrupted their patterns of consumption (including abstinence) but then allowed their continuation. As Grace (58) explained, moving from a city to a regional town two hours' train ride away presented difficulties for maintaining her desired pattern of heroin consumption. Having taken heroin regularly since her twenties while living in the big city where she was born, Grace but also took up opioid pharmacotherapy treatment (OPT), most recently Suboxone, when struggling financially. She describes difficulties accessing OPT and heroin after moving to a new town because of limited services and reduced social network. As she explained, 'We tried to get a doctor here but apparently there was only one [who prescribes Suboxone] and he's really hard to get in to see'. As a result, Grace said, she and her partner continued to travel back to the city to visit their OPT doctor and their long-time heroin supplier:

We'd go down to [the city to] someone who we used to know for 25 years [...]

We just ring him up and say, 'Oh hi, coming down on whatever [day]' and catch a train down, meet up with them [to buy heroin].

In order to be able to continue to take heroin in the way she preferred, Grace had to maintain her connection to the city by travelling there on her day off work. This unbroken contact constituted a continuous spatio-temporal entanglement despite the disruption of her move to a regional town. 
Unlike Grace, Barry (40) said he specifically sought to disrupt his heroin use and remain abstinent when relocating from his home city to a regional town a few hours' drive away to live with his mother. The move enabled him to connect to a number of resources in the town to create what he called his 'safety net' that would 'pull [him] up' when he felt 'vulnerable' to resuming heroin use:

I've got a great GP [doctor] who I can call in and see whenever I want. If I'm not coping, I can ring up and make an appointment and just go in and talk. I do a lot of journaling, you know, which helps [...Since] I moved up here [...] I've done more therapy-and good, solid, really to-the-bones-of-it therapythan I've done in the last over-20 years [...] Because l'm on 90 milligrams of methadone [...] I really don't get much [of a 'buzz' from taking heroin...] it's a waste of cash [...] So that's an extra way of keeping myself safe.

Along with his journaling, counselling, visits to the doctor and methadone maintenance treatment (MMT), Barry says living with his mother helped as she managed his cash, and held him accountable for his spending. As he puts it, isolation from the city was a significant benefit of living in the town, as he was able to avoid driving past the place where he used to buy heroin. The safety net Barry described was rooted in the regional town and relied upon distance from the city to work. However, Barry also said his mother was considering moving back to the city, and he anticipated returning too. Could the city become a new kind of place for Barry, in which his new spatio-temporal intra-actions could find further connections that would sustain their effect on his consumption patterns? Unsure, Barry said he aimed to maintain his safety net in order to sustain his non-consumption should the move occur, and also planned to set up a similar safety net back in the city. In Barad's terms, the safety net in Barry's account could be understood as an intra-active relation in which healthcare services, living arrangements, his relationship with his mother, restricted access to cash, methadone maintenance treatment and the location of his work appeared to produce and sustain his non-consumption, but only while the relations remained intact. New intra-actions would be needed if the old ones broke down.

In the accounts in this section, brief disruptions as a result of particular spatiotemporalities were followed by a return to past patterns. Barry and Grace's accounts enacted moving as a force that could bring about change, either welcome or unwelcome, and presented the maintenance of particular patterns as a relational achievement. More than the outcome of individual agency alone, continuity involved the ongoing iteration of a diverse range of human and non-human practices and 
spatio-temporal relations to generate desired effects - consumption or abstinence. Reading these accounts through Barad's notions of intra-action and spatiotemporality, continuity in both consumption and non-consumption patterns cannot be understood as simply the product of individual acts of will or internal causes. By extension, we argue that these accounts enact agency not as the sole prerogative of human subjects but rather as created through particular spatio-temporal relations. The consumption patterns in these accounts can be said to emerge, continue or change through the particular spatio-temporalities arising in times of relocation. Here, our analysis brings into focus the new opportunities moving could afford for sustaining consumption patterns or abstinence.

\section{Conclusion}

In drawing out the spatio-temporal dynamics articulated in these stories of residential relocation, what emerges is both the wide range of relocation experiences described, and their diverse effects on alcohol and other drug consumption patterns. The ubiquity of disruption or change in times of relocation, we would argue, clearly illuminates the indivisibility of spatio-temporalities from patterns of drug use. Even where patterns appeared to be maintained in times of relocation, these were not the stable, compulsive and self-perpetuating practices found in popular accounts of addiction. Continuity was a tenuous achievement: patterns had to be carefully and collectively re-created in the midst of new relational opportunities and imperatives, localised in particular spatio-temporalities. The relations in which participants found themselves after moving played a key role in facilitating or impeding previous practices. From this point of view, individuals and their agencies emerge in highly situated ways. They are phenomena, intra-actively made in specific spatio-temporal entanglements. When these change, so too do individuals, their capacities, agencies and their patterns of consumption. This insight highlights an important limitation in common understandings and narratives of alcohol and other drug addiction that rely solely on the individual. Locating the origins and causes of consumption within the individual human body or brain creates difficulties in accounting for the wide variation in practices as people move and become engaged in different relations. It also pathologises individuals, presenting events and patterns as individual characteristics and effects.

While researchers have long acknowledged the importance of environment for shaping drug use (e.g. Alexander, Hadaway \& Coambs, 1980; Zinberg, 1986) little effort has been made to attend to the changes over time that places, and people's 
relations with them, undergo. This is another way of saying that space or place only exists insofar as it exists in time and, as such, all spaces and places are subject to the changes time brings. Working with static conceptions of place, context and environment limits our ability to attend to these changes and their effects on consumption over time. In particular, treating place as stable overdetermines accounts in which people who have moved return to consumption, effectively assessing this as relapse caused by a flaw within. If changing the external context did not help, the problem must lie within. Where place is no longer seen as static nor external, however, it can be properly identified as active in the production of new (or resumed) patterns of consumption. In turn, stigmatising conceptions of addiction and relapse can be avoided. By incorporating temporality into the analysis of place, the processes by which patterns emerge becomes clearer.

Similarly, relations can be interpreted more easily as always in flux due to the constant movements in time and space of people, material objects, meanings and practices. As we have seen, consumption patterns, living arrangements and engagements with various places typically shift many times over the course of a life. This dynamism invites further attention and analysis to allow our understandings of drug use to move beyond snapshots in time. Further, this attentiveness to spatiotemporality may help us exceed all-too-common linear accounts of addiction, presented as an arc of decline, collapse and finally redemption only when drugs are renounced (Keane, 2002). Such accounts elide and fail to do justice to these constant modulations in consumption patterns. Within our more dynamic approach, continuity becomes a product of constant reiteration, rather than a guaranteed effect of a stable cause. Patterns of heavy regular consumption seen as the hallmark of addiction become less the property of individual 'addicts', less the quality or entailment of a particular place, and instead the emergent effect of highly situated intra-actions.

Viewed from the point of view of this analysis, the scepticism surrounding notions of 'doing a geographical' or relocating for the purpose of changing consumption, relies on two related problematic assumptions: first that places once encountered remain the same forever after, becoming a stable 'factor' at best enabling or constraining individual aspirations; and second that the problem of addiction resides within the individual, travelling with that individual wherever relocation takes them, certain to ultimately re-emerge regardless of context. As we have suggested, place cannot be regarded as passive, having no role in fostering relations that may enable change. 
Rather, relocation may offer people access to different resources, while dislocating them from the unwanted effects of previous places. Of course, relocation does not always produce positive effects, but as our participants' accounts illustrate, with a particular mix of resources and relations, new spatio-temporalities sometimes initiated and afforded ongoing positive change.

This observation leads us to consider how the spatio-temporalities of consumption patterns may be more actively integrated into public health and other initiatives aimed at supporting people with heavy regular alcohol and other drug consumption patterns. Where people are mobile, this movement needs to be considered as a key dimension of place-based services. How are the resources necessary for continuity of care maintained in the spatio-temporality of place, most obviously in times of relocation? Several of our accounts show the importance of transitions into and out of residential treatment and custody, making clear the ways treatment access can be affected by relocation, and suggesting the need for further support for post-treatment and post-release care. Notably, for those not looking to, or obliged to, move the question becomes how the dynamic and changing nature of existing places may be mobilised to support those wishing to disrupt their patterns of consumption over time without moving. How might existing places and their effects be made anew in novel spatio-temporal entanglements? Attending to the situated ways in which consumption patterns are generated, disrupted and maintained over space and time allows for new strategies and approaches. In turn it casts into question the essentialising and stigmatising treatment of heavy regular consumption as 'addiction' - as the individual failure, flaw or disorder that always catches up with us. 


\section{APPENDIX 1}

Table: Data characteristics $(\mathrm{N}=60)$

\begin{tabular}{|c|c|}
\hline Gender^ & Number \\
\hline Men & 35 \\
\hline Women & 25 \\
\hline \multicolumn{2}{|l|}{ Main preferred drug* } \\
\hline Alcohol & 11 \\
\hline Cannabis & 14 \\
\hline Opiates & 14 \\
\hline Stimulants & 12 \\
\hline 'Party drugs' (e.g. MDMA, GHB, Ketamine) & 4 \\
\hline Prescription \& over-the-counter drugs & 5 \\
\hline \multicolumn{2}{|l|}{ Age } \\
\hline $18-29$ & 14 \\
\hline $30-39$ & 20 \\
\hline $40-49$ & 14 \\
\hline $50+$ & 12 \\
\hline \multicolumn{2}{|l|}{ Cultural and ethnic background } \\
\hline Australian & 31 \\
\hline Australian Aboriginal & 2 \\
\hline New Zealander & 1 \\
\hline Polynesian & 2 \\
\hline North-West European & 12 \\
\hline Southern \& Eastern European & 4 \\
\hline North African \& Middle Eastern & 1 \\
\hline South-East Asian & 1 \\
\hline North-East Asian & 2 \\
\hline North American & 2 \\
\hline Southern \& Eastern African & 2 \\
\hline \multicolumn{2}{|l|}{ Sexual identity } \\
\hline Heterosexual & 41 \\
\hline LGBTIQ+ & 18 \\
\hline Unspecified & 1 \\
\hline \multicolumn{2}{|l|}{ Education level } \\
\hline Secondary & 26 \\
\hline Post-secondary & 12 \\
\hline Tertiary & 22 \\
\hline \multicolumn{2}{|l|}{ Employment status } \\
\hline Working/studying & 41 \\
\hline Not working/studying & 19 \\
\hline \multicolumn{2}{|l|}{ Location } \\
\hline Major urban - Victoria: Melbourne & 21 \\
\hline Regional - Victoria: Bendigo & 9 \\
\hline Major urban - New South Wales: Sydney & 19 \\
\hline $\begin{array}{l}\text { Regional - New South Wales: Byron Bay, } \\
\text { Lismore \& Nimbin }\end{array}$ & 11 \\
\hline
\end{tabular}

^All participants identified either as male or female.

* Some participants described consuming only one drug, while others talked about two or more. The table lists the drug that participants identified as their primary preferred drug.

Reporting of cultural and ethnic background follows the Australian Standard Classification of Cultural and Ethnic Groups, developed by the Australian Bureau of Statistics. Cultural and ethnic background was classified according to a combination of self-reported group identification with particular cultural or ethnic groups, the participant's birthplace and their parents' birthplaces. 


\section{References}

Adey, P., Bissell, D., Hannam, K., Merriman, P., \& Sheller, M. (2014). The Routledge handbook of mobilities. London: Routledge.

Alcoholics Anonymous Australia. (2016). Glossary of terms used in AA. Retrieved 8 November, 2016, from http://www.aa.org.au/new-to-aa/glossary-ofterms.php\#Geographical

Alexander, B. K., Hadaway, P., \& Coambs, R. (1980). Rat park chronicle. British Columbia Medical Journal, 22(2), 32-45.

American Psychiatric Association. (2013). Diagnostic and Statistical Manual of Mental Disorders, Fifth Edition. Washington DC: American Psychiatric Press.

Barad, K. (1998). Getting real: Technoscientific practices and the materialization of reality. Differences: A Journal of Feminist Cultural Studies, 10(2), 87-128.

Barad, K. (2001). Re(con)figuring space, time, and matter. In M. Dekoven (Ed.), Feminist locations: Global and local, theory and practice (pp. 75-109). New Brunswick, New Jersey and London: Rutgers University Press.

Barad, K. (2003). Posthumanist performativity: Toward an understanding of how matter comes to matter. Signs: Journal of Women in Culture and Society, 28(3), 801-831.

Bourgois, P. I., \& Schonberg, J. (2009). Righteous dopefiend. Berkeley and Los Angeles, CA: University of California Press.

Cooper, H. L. F., \& Tempalski, B. (2014). Integrating place into research on drug use, drug users' health, and drug policy. International Journal of Drug Policy, 25(3), 503-507.

Cooper, H. L., Bonney, L. E., Ross, Z., Karnes, C., Hunter-Jones, J., Kelley, M. E., \& Rothenberg, R. (2013). The aftermath of public housing relocation: Relationship to substance misuse. Drug \& Alcohol Dependence, 133(1), 37-44.

Cummins, S., Curtis, S., Diez-Roux, A. V., \& Macintyre, S. (2007). Understanding and representing 'place' in health research: A relational approach. Social Science \& Medicine, 65(9), 1825-1838.

DeGrandpre, R. (2006). The cult of pharmacology: How America became the world's most troubled drug culture. Durham, NC: Duke University Press.

DeWit, D. J. (1998). Frequent childhood geographic relocation: Its impact on drug use initiation and the development of alcohol and other drug-related problems among adolescents and young adults. Addictive Behaviors, 23(5), 623-634.

Dilkes-Frayne, E. (2014). Tracing the "event" of drug use: "Context" and the coproduction of a night out on MDMA. Contemporary Drug Problems, 41(3), 445-479. 
Duff, C. (2011). Networks, resources and agencies: On the character and production of enabling places. Health \& Place, 17(1), 149-156.

Duff, C. (2014). The place and time of drugs. International Journal of Drug Policy, 25(3), 633-639.

Duff, C., \& Moore, D. (2014). Going out, getting about: Atmospheres of mobility in Melbourne's night-time economy. Social \& Cultural Geography, 16(3), 299-314.

Fraser, S. (2006). The chronotope of the queue: Methadone maintenance treatment and the production of time, space and subjects. International Journal of Drug Policy, 17(3), 192-202.

Fraser, S., Moore, D., \& Keane, H. (2014). Habits: Remaking addiction. London: Palgrave Macmillan.

Fraser, S., \& valentine, k. (2008). Substance and substitution: Methadone subjects in liberal societies. Basingstoke: Palgrave Macmillan.

Fry, C., \& Dwyer, R. (2001). For love or money? An exploratory study of why injecting drug users participate in research. Addiction, 96(9), 1319-1325.

Genberg, B. L., Gange, S. J., Go, V. F., Celentano, D. D., Kirk, G. D., Latkin, C. A., \& Mehta, S. H. (2011). The effect of neighborhood deprivation and residential relocation on long-term injection cessation among injection drug users (IDUs) in Baltimore, Maryland. Addiction, 106(11), 1966-1974.

Granfield, R., \& Cloud, W. (1999). Coming clean: Overcoming addiction without treatment. New York and London: New York University Press.

Green, T. C., \& Pope, C. (2008). Using a GIS framework to assess hurricane recovery needs of substance abuse centre clients in Katrina- and Rita-affected areas. In Y. F. Thomas, D. Richardson \& I. Cheung (Eds.), Geography and drug addiction (pp. 369-393) Netherlands: Springer.

Health Experiences Research Group (HERG). (2010). Researcher's Handbook for Producing HealthTalkOnline and YouthHealthTalk Websites. Health Experiences Research Group, Oxford University: Oxford.

Hser, Y-I., Longshore, D., \& Anglin, M. D. (2007). The life course perspective on drug use a conceptual framework for understanding drug use trajectories. Evaluation Review, 31(6), 515-547.

Jackson, A. Y., \& Mazzei, L. A. (2011). Thinking with theory in qualitative research: Viewing data across multiple perspectives. Abingdon: Routledge.

Jayne, M., Gibson, C., Waitt, G., \& Valentine, G. (2012). Drunken mobilities: Backpackers, alcohol, 'doing place'. Tourist Studies, 12(3), 211-231. 
Jayne, M., Valentine, G., \& Holloway, S. (2016), 'Consumption and Context'. In T. Kolind, B. Thom \& G. Hunt, (Eds), The SAGE Handbook of Drug \& Alcohol Studies: Social Science Approaches (pp. 352-364). London: Sage Publications. Keane, H. (2002). What's wrong with addiction? Melbourne: Melbourne University Press.

Linton, S. L., Cooper, H. L., Luo, R., Karnes, C., Renneker, K., Haley, D. F., HunterJones, J., Ross, Z., Bonney, L., \& Rothenberg, R. (2016). People and places: Relocating to neighborhoods with better economic and social conditions is associated with less risky drug/alcohol network characteristics among African American adults in Atlanta, GA. Drug and Alcohol Dependence, 160, 30-41.

Love, M., Wilton, R., \& DeVerteuil, G. (2012). 'You have to make a new way of life': women's drug treatment programmes as therapeutic landscapes in Canada. Gender, Place and Culture, 19(3), 382-396.

Maddux, J. F., \& Desmond, D. P. (1982). Residence relocation inhibits opioid dependence. Archives of General Psychiatry, 39(11), 1313-1317.

Malins, P., Fitzgerald, J. L., \& Threadgold, T. (2006). Spatial 'folds': The entwining of bodies, risks and city spaces for women injecting drug users in Melbourne's central business district. Gender, Place and Culture, 13(5), 509-527.

Martinez, A. N., Lovrick, J., \& Kral, A. H. (2014). Activity spaces among injection drug users in San Francisco. International Journal of Drug Policy, 25(3), 516-524.

Massey, D. (2005). For space. London: Sage Publications.

Mayock, P. (2002). Drug pathways, transitions and decisions: The experiences of young people in an inner-city Dublin community. Contemporary drug problems, 29(1), 117-156.

Moore, D. (1992). Deconstructing dependence: An ethnographic critique of an influential concept. Contemporary Drug Problems, 19(3), 459-490.

Moore, D. (2004). Governing street-based injecting drug users: A critique of heroin overdose prevention in Australia. Social Science \& Medicine, 59(7), 1547-1557.

Moore, D., \& Dietze, P. (2005). Enabling environments and the reduction of drugrelated harm: Re-framing Australian policy and practice. Drug and Alcohol Review, 24(3), 275-284.

Morris, T., Manley, D., \& Sabel, C. E. (2016). Residential mobility: Towards progress in mobility health research. Progress in Human Geography (Online ahead of print).

Murdoch, J. (2006). Post-structuralist geography: A guide to relational space. London: Sage Publications. 
Parkin, S. (2013). Habitus and drug using environments: Health, place and livedexperience. Surrey: Ashgate.

Pienaar, K., Moore, D., Fraser, S., Kokanovic, R., Treloar, C., \& Dilkes-Frayne, E. (2016). Diffracting addicting binaries: An analysis of personal accounts of alcohol and other drug 'addiction'. Health: An Interdisciplinary Journal for the Social Study of Health, Illness and Medicine (Online ahead of print).

Poulsen, M. (2015). Embodied subjectivities: Bodily subjectivity and changing boundaries in post-human alcohol practices. Contemporary Drug Problems, 42(1), 3-19.

Rainham, D., McDowell, I., Krewski, D., \& Sawada, M. (2010). Conceptualizing the healthscape: Contributions of time geography, location technologies and spatial ecology to place and health research. Social Science \& Medicine, 70(5), 668676.

Rhodes, T. (2002). The 'risk environment': A framework for understanding and reducing drug-related harm. International Journal of Drug Policy, 13(2), 85-94.

Riaño-Alcalá, P. (2010). Dwellers of memory: Youth and violence in Medellin, Colombia. New Brunswick and London: Transaction Publishers.

Seear, K. (2013). What do we really know about doping 'effects'? An argument for doping effects as co-constituted 'phenomena'. Performance Enhancement \& Health, 2(4), 201-209.

Stabler, M. E., Gurka, K. K., \& Lander, L. R. (2015). Association between childhood residential mobility and non-medical use of prescription drugs among American youth. Maternal and Child Health Journal, 19(12), 2646-2653.

Summerson Carr, E. (2011). Scripting addiction: The politics of therapeutic talk and American sobriety. Princeton and Oxford: Princeton University Press.

Waldorf, D., Reinarman, C., \& Murphy, S. (1992). Cocaine changes: The experience of using and quitting. Philadelphia: Temple University Press.

Williams, L. (2012). Changing lives, changing drug journeys: Drug taking decisions from adolescence to adulthood. Abingdon: Routledge.

Wilton, R., \& Moreno, C. M. (2012). Critical geographies of drugs and alcohol. Social \& Cultural Geography, 13(2), 99-108.

World Health Organization. (1992). The ICD-10 Classification of diseases and related health problems. Geneva: World Health Organization.

Zinberg, N. E. (1986). Drug, set, and setting: The basis for controlled intoxicant use. New Haven: Yale University Press. 
i Those who responded to the recruitment flyer were screened to ensure we recruited participants with a pattern of alcohol or other drug consumption that would qualify them for a diagnosis of 'substance use disorder' or 'dependence syndrome', the terms for 'addiction' in two influential diagnostic instruments, namely the Diagnostic and Statistical Manual (DSM-5) (American Psychiatric Association, 2013) and the International Classification of Diseases (ICD-10) (World Health Organization, 1992). Respondents were identified as eligible to participate if they referenced at least three of the DSM-5 or ICD-10 criteria, which would qualify them for a diagnosis of 'substance use disorder' (DSM-5), or 'dependence syndrome' (ICD-10). 